\title{
Wear and Electrochemical Corrosion Behavior of Biomedical Ti-25Nb-3Mo-3Zr-2Sn Alloy in Simulated Physiological Solutions
}

\author{
Weijiu Huang • Zhenguo Wang • Chenglong Liu • \\ Yongmei Yu
}

Received: 19 June 2014/Revised: 30 August 2014/ Accepted: 1 September 2014/Published online: 15 October 2014

(c) Springer International Publishing AG 2014

\begin{abstract}
The wear and electrochemical corrosion behavior of the biomedical $\mathrm{Ti}-25 \mathrm{Nb}-3 \mathrm{Mo}-3 \mathrm{Zr}-2 \mathrm{Sn}$ (TLM) titanium alloy was investigated in various simulated physiological solutions. Different simulated physiological solutions comprised phosphate-buffered solution (PBS), PBS with bovine serum albumin (PBS+BSA), and PBS with hyaluronic acid (PBS+HA) were employed. A potentiostat and a reciprocating friction and wear tester were used to study the wear and corrosion behavior of the TLM alloy. The influence of the chemical composition of the simulated solutions on the tribo-electrochemical behavior was considered by potentiodynamic studies under reciprocating friction and wear conditions. It was found that the corrosion tendency of the TLM alloy was the most obvious in PBS+HA under static corrosion condition, while it was just opposite with wear. Compared with static corrosion, the corrosion resistance of the TLM alloy was decreased with sliding conditions. The values of $i_{\text {corr }}$ were two orders of magnitude higher than those at static corrosion. This phenomenon shows that the wear accelerated corrosion. Under coexisting condition of both electrochemical corrosion and wear, the wear rate of the TLM alloy mutually influenced by both factors will be accelerated. Plastic
\end{abstract}

W. Huang $(\bowtie) \cdot$ Z. Wang $\cdot$ C. Liu $\cdot$ Y. Yu

School of Materials Science and Engineering, Chongqing

University of Technology, No. 69, HongGuang Avenue, BaNan

Distirct, Chongqing 400054, People's Republic of China

e-mail: huangweijiu@cqut.edu.cn

Z. Wang

e-mail: wzghappy@yeah.net

Z. Wang

Grikin Advanced Materials Co., Ltd, No. 33 Chaoqian Rd.

Changping Sci \& Tech Park, Beijing 102200,

People's Republic of China grooves and deformation were observed on the worn surfaces of the TLM alloy by scanning electron microscopy (SEM). Through the observation of SEM, the tribological mechanism was a typical corrosive wear, and the main wear mechanisms were abrasive with adhesive wear under the interaction between corrosion and wear. The XPS results show that the passive films include the $\mathrm{TiO}_{2}, \mathrm{ZrO}_{2}$, $\mathrm{Nb}_{2} \mathrm{O}_{5}, \mathrm{Mo}_{2} \mathrm{O}_{5}$, and $\mathrm{Sn}_{2} \mathrm{O}_{3}$.

Keywords Titanium alloy · Ti-25Nb-3Mo-3Zr-2Sn . Electrochemical corrosion - Simulated physiological solutions · Tribo-electrochemical · Wear and corrosion

\section{Introduction}

As biomaterial, titanium and its alloys have high specific strength to weight ratio, excellent corrosion resistance, good mechanical properties, in addition to exceptional biocompatibility [1-4]. Among titanium alloys for medical implants, Ti-6Al-4V alloy is the most frequently used $[4,5]$. But in the case of Ti-6Al-4V alloy, there is another problem-aluminum and vanadium may cause long-term health problems $[2,5-8]-$ e.g., aluminum, it is possible relation to Alzheimer's disease [5, 8]. In early stage, the titanium alloys composed of nontoxic elements that have been developed are mainly $\alpha+\beta$ type ones. Therefore, the trend in research and development of titanium alloys for biomedical applications is to develop $\beta$ titanium alloys composed of nontoxic elements such as $\mathrm{Nb}, \mathrm{Ta}, \mathrm{Zr}$, Mo, and Sn [9-11]. These alloys have lower elasticity modulus, higher strength, excellent corrosion resistance, and better toughness to compar with the $\alpha$ and $\alpha+\beta$ titanium alloys $[9,10]$. Hence, a metastable $\beta$ titanium alloy, Ti-25Nb$3 \mathrm{Mo}-3 \mathrm{Zr}-2 \mathrm{Sn}$ (TLM) containing the nontoxic elements $\mathrm{Nb}$, 
$\mathrm{Zr}$, Mo, and Sn, was developed as biomedical material, which is suitable for implant applications [12-16]. The TLM alloy exhibits significant improvement in these properties compared to the previous generation titanium alloys, such as C.P. titanium and Ti-6Al-4V alloy. It has a low elastic modulus, high strength, and exhibits considerable plasticity as well as pseudo-elastic characteristic $[15,16]$.

Wear and corrosion are two of the most frequently encountered failure modes for mechanical components working under aggressive service conditions [17]. Wearcorrosion is the degradation of material under simultaneous removal by mechanical wear and corrosion [17-19]. Under the conditions of wear and corrosion, the total removal rate is usually not the sum of corrosion rate and wear rate measured in separate tests $[18,19]$. Usually, corrosion is accelerated by wear, and similarly wear may be accelerated or slowed down by corrosion [19]. Hence, a number of titanium alloys have been employed to study the wear and corrosion behavior in different simulated physiological solutions [20-26].

However, few investigations have been reported on the reciprocating wear and electrochemical corrosion behavior of the $\mathrm{Ti}-25 \mathrm{Nb}-3 \mathrm{Mo}-3 \mathrm{Zr}-2 \mathrm{Sn}$ (TLM) alloy. Therefore, this work will research the wear and corrosion behavior of the TLM alloy in simulated physiological solutions. The potentiodynamic polarization curves, friction coefficient, wear rate, wear-corrosion morphologies, and the composition of passive films will be obtained.

\section{Experimental}

\subsection{Sample Preparation}

TLM alloy was supplied by Northwest Institute for Nonferrous Metal Research as a rolled plate with $4.0 \mathrm{~mm}$ thickness. The chemical composition of the TLM alloy is given in Table 1. As-received plates of the TLM alloy were used. The test samples were machined into rectangular strips with a dimension of $35.0 \times 25.0 \times 3.5 \mathrm{~mm}$ by wireelectrode cutting. Surfaces of test samples were mechanically polished with $\mathrm{SiC}$ water proof abrasive papers followed as 200\#, 400\#, 600\#, 800\#, 1000\#, and 1200\#, and then cleaned ultrasonically in acetone, ethanol, and distilled water for $10 \mathrm{~min}$, respectively, and dried under a cold air stream through an electric hair dryer finally. The surface roughness $(\mathrm{Ra})$ of the polished samples was between 0.061 and $0.062 \mu \mathrm{m}$.

Table 1 Chemical composition of the Ti-25Nb-3Mo-3Zr-2Sn alloy (wt\%)

\begin{tabular}{llllllllll}
\hline $\mathrm{Ti}$ & $\mathrm{Nb}$ & $\mathrm{Mo}$ & $\mathrm{Sn}$ & $\mathrm{Zr}$ & $\mathrm{C}$ & $\mathrm{N}$ & $\mathrm{H}$ & $\mathrm{O}$ & $\mathrm{Fe}$ \\
\hline Bal. & 25.1 & 2.90 & 2.02 & 3.08 & 0.01 & 0.03 & 0.003 & 0.14 & 0.03 \\
\hline
\end{tabular}

\subsection{Simulated Physiological Solutions}

Phosphate-buffered solution (PBS) is a simulated body fluid commonly used in biomedical research for implant materials applications [27, 28]. In order to simulate the physiological conditions of human, PBS was chosen for the electrolyte. For comparison, bovine serum albumin (BSA) and Sodium Hyaluronate were added in the PBS, respectively. Hence, there are three different electrolytes that were used: Phosphate-Buffered Solution (PBS) with the composition of $8.0 \mathrm{~g} / \mathrm{L} \mathrm{NaCl}, 0.2 \mathrm{~g} / \mathrm{L} \mathrm{KCl}, 1.15 \mathrm{~g} / \mathrm{L} \mathrm{Na}_{2} \mathrm{HPO}_{4}$, and $0.2 \mathrm{~g} / \mathrm{L}$ $\mathrm{KH}_{2} \mathrm{PO}_{4}$, a PBS with the addition of $10 \mathrm{~g} / \mathrm{L}$ of BSA and a PBS with the addition of $10 \mathrm{~g} / \mathrm{L}$ of Sodium Hyaluronate which was considered the effect of the hyaluronic acid (HA). BSA was supplied by Sigma-Aldrichin in United States, and Sodium Hyaluronate was supplied by Shanghai yuanye BioTechnology Co., Ltd in China. The buffered solutions were adjusted to $\mathrm{pH} 7.4 \pm 0.2$ by acid-base balance fluid, and the test temperature was maintained at $37 \pm 1.0^{\circ} \mathrm{C}$. All chemicals were of analytical grade, and doubly distilled water was employed in the preparation of these solutions, and fresh solution was provided for each test.

\subsection{Wear-Corrosion Tests}

The wear-corrosion experiments were carried out in simulated physiological solutions with a wear equipment to investigate the behavior of the TLM alloy under the synergistic attacks of corrosion and wear. The experimental apparatus for wearcorrosion tests is shown in Fig. 1, which is composed of a potentiostat (model CS350, China) and a reciprocating friction and wear tester (model MFT-R4000, China).

All the results of electrochemical corrosion tests were acquired by using the potentiostat with a typical threeelectrode test system. The system fitted with a platinum sheet as counter electrode (CE), sample as working electrode (WE) and saturated calomel electrode (SCE) as

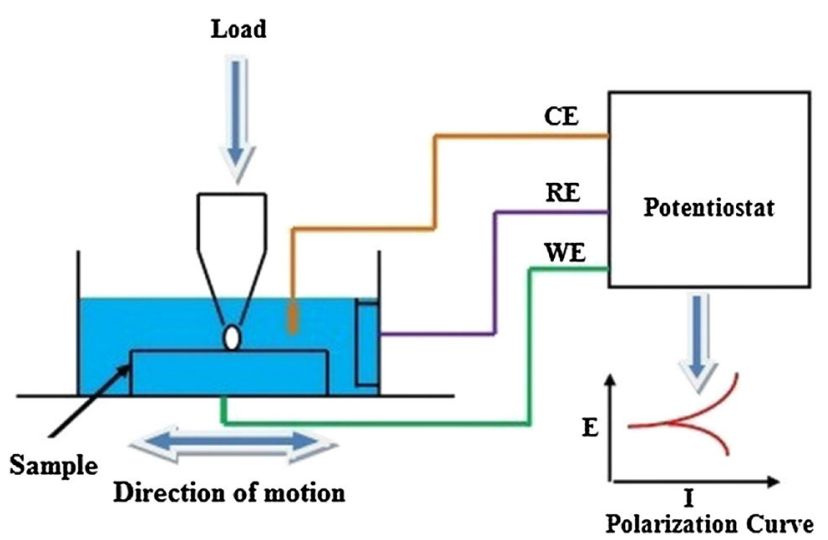

Fig. 1 Experimental apparatus for wear-corrosion tests: $C E$ counter electrode, $W E$ working electrode, $R E$ reference electrode 
Table 2 Physical properties of $\mathrm{Si}_{3} \mathrm{~N}_{4}$ ceramic ball

\begin{tabular}{llllll}
\hline $\begin{array}{l}\text { Ceramics } \\
\text { ball }\end{array}$ & $\begin{array}{l}\text { Density } \\
\left(\mathrm{g} \mathrm{cm}^{-3}\right)\end{array}$ & $\begin{array}{l}\text { Thermal expansion } \\
\text { coefficient }\left(10^{-6} \mathrm{k}^{-1}\right)\end{array}$ & $\begin{array}{l}\text { Poisson's } \\
\text { ratio }\end{array}$ & $\begin{array}{l}\text { Hardness } \\
(\mathrm{Hv})\end{array}$ & $\begin{array}{l}\text { Elastic modulus } \\
(\mathrm{GPa})\end{array}$ \\
\hline $\mathrm{Si}_{3} \mathrm{~N}_{4}$ & 3.25 & 3.2 & 0.26 & 1,500 & 310 \\
\hline
\end{tabular}

reference electrode (RE). The potentiodynamic polarization curves were obtained in the range from $-1.0 \mathrm{~V}$ with respect to open-circuit potential (OCP) to $1.0 \mathrm{~V}$ (vs. SCE) using a scan rate of $1 \mathrm{mV} / \mathrm{s}$.

The wear tests were carried on using a reciprocating friction and wear tester. The friction pair is $\mathrm{Si}_{3} \mathrm{~N}_{4}$ ceramic ball with $3 \mathrm{~mm}$ in diameter; its physical properties are shown in Table 2, and it was supplied by Lanzhou Zhongke Technology Co., Ltd. The step length of reciprocating friction is $10 \mathrm{~mm}$. The loads of 20 and $30 \mathrm{~N}$ were used, while the friction frequencies were 2 and $5 \mathrm{~Hz}$. The total friction time is $23 \mathrm{~min}$ for each test. The surface roughness $(\mathrm{Ra})$ of the tested samples was between 0.088 and $0.095 \mu \mathrm{m}$. Experiments were triplicated for each test under different conditions.

\subsection{Analytical Methods}

After tests, potentiodynamic polarization curves can be obtained. According to the polarization curves, the corrosion potential $\left(E_{\text {corr }}\right)$ and corrosion current density $\left(i_{\text {corr }}\right)$ could be acquired by the extrapolation method of Tafel.

The wear volumes of the TLM alloy were measured by a non-contact 3D surface profiler (NanoMap500LS, United States). Then the wear rates of the TLM alloy are calculated through the Eq. 1 [29].

$W=V /(N L)$

where $V$ is the wear volume $\left(\mathrm{mm}^{3}\right), N$ is the normal load $(\mathrm{N})$, and $L$ is the sliding distance $(\mathrm{mm})$.

The morphologies and composition of the wear scars, material transfer, and wear debris were observed and analyzed by using scanning electron microscopy (SEM, JSM-6460LV), X-ray diffractometry (XRD, X' Pert PRO MPO), and X-ray photoelectron spectroscopy (XPS, KRA TO S2XSAM 800).

\section{Results and Discussion}

\subsection{Potentiodynamic Polarization Curves}

\subsubsection{Curves Without Wear}

Figure 2 shows typical potentiodynamic polarization curves of the TLM alloy in different simulated physiological solutions. The corrosion parameters determined

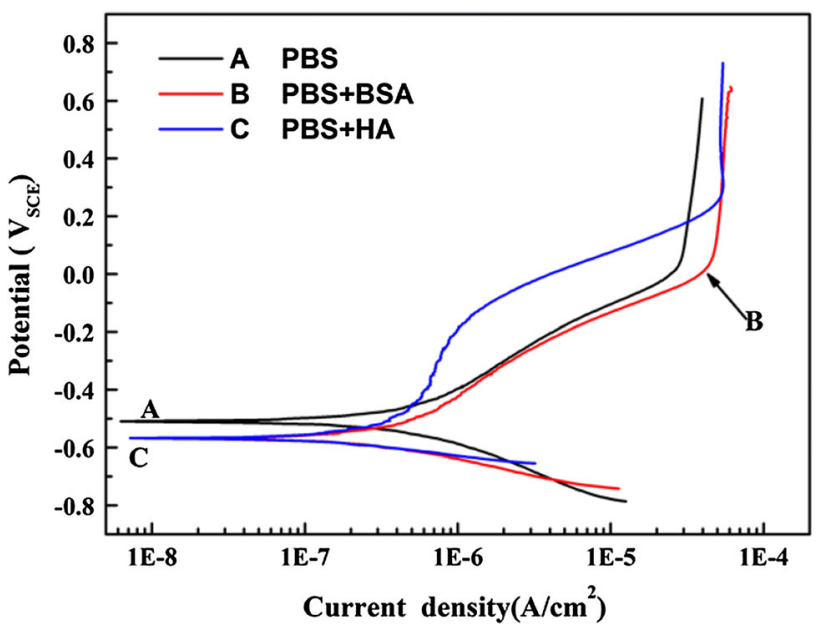

Fig. 2 Potentiodynamic polarization curves of the $\mathrm{Ti}-25 \mathrm{Nb}-3 \mathrm{Mo}-$ $3 \mathrm{Zr}-2 \mathrm{Sn}$ alloy under different simulated physiological solutions without wear

from the Tafel region of the polarization curves are given in Table 3. Tafel analysis indicates that the corrosion potentials, $E_{\text {corr }}$, in the PBS+BSA and PBS+HA solutions are similar, but the values of $E_{\text {corr }}$ in the two solutions are more negative than those in the PBS. It is well known that the more positive the $E_{\text {corr }}$, the material is more difficult to corrosion. As can be seen from Fig. 2, the $E_{\text {corr }}$ in PBS+BSA are more negative than those in PBS invariably at any point in time, and the results suggest that the addition of BSA increases the corrosion tendency of the TLM alloy. The results are consistent with the results of C. Valero et al. [29] and Cheng et al. research [30]. BSA acts as inhibitor of the cathodic process and accelerates the anodic reaction. The inhibition influence can be explained by the presence of adsorbed BSA that may impede the access of the oxidant to the metallic surface $[29,30]$. For another, the adsorption of the protein can bind to metal ions and transport them away from interface between the solution and passive film [31]. The corrosion current density is the same order of magnitude in different solutions, and the value of $i_{\text {corr }}$ in PBS+HA is the biggest. HA has higher viscosity, when it was adsorbed on the surface of the TLM alloy, it would refrain the diffusion of $\mathrm{O}$ and $\mathrm{Ti}$ ions, reduce the rate of oxygen reduction reaction and slow down the speed of the formation of the passive film on the surfaces of the samples [30]. Without the protection of the passivation film, the corrosion rate would increase in PBS+HA. 
Table 3 Corrosion parameters of the Ti-25Nb-3Mo-3Zr-2Sn alloy in different simulated physiological solutions

\begin{tabular}{lll}
\hline Simulated physiological solutions & $E_{\text {corr }}(\mathrm{V})$ & $i_{\text {corr }}\left(\times 10^{-7} \mathrm{~A} \mathrm{~cm}^{-2}\right)$ \\
\hline PBS & -0.51 & 1.31 \\
PBS+BSA & -0.56 & 5.45 \\
PBS +HA & -0.57 & 2.44 \\
\hline
\end{tabular}

Table 4 Corrosion parameters of C.P. Ti and Ti-6Al-4V in PBS solution at $37{ }^{\circ} \mathrm{C}$ [27]

\begin{tabular}{lll}
\hline Alloy & $E_{\text {corr }}(\mathrm{V})$ & $i_{\text {corr }}\left(\times 10^{-7} \mathrm{~A} \mathrm{~cm}^{-2}\right)$ \\
\hline CP-Ti & -0.39 & 3.3 \\
Ti-6Al-4V & -0.69 & 1.8 \\
\hline
\end{tabular}

It is also can be seen that both BSA and HA increased the cathodic current and moved the OCP in the negative direction. The effect was most dramatic with the addition of HA (Table 3). It is well known that many organic corrosion inhibitors prevent corrosion by forming an adsorbed film and blocking the mass transportation during the process of corrosion; the proteins have high affinity for adsorption onto metal alloy surfaces [30].

Bai et al. [27] reported the values of $E_{\text {corr }}$ and $I_{\text {corr }}$ of the C.P. Ti and Ti-6Al-4V samples in the PBS solution at $37^{\circ} \mathrm{C}$, and the values are listed in Table 4 . The results show that the TLM alloy has lower corrosion rate in the same corrosion conditions, compared with C.P. Ti and Ti6Al-4 V alloys. This is probably due to the constitution of the protective oxide film formed on the surface of the TLM alloy, and Bai et al. obtained the similar results [27].

\subsubsection{Curves with Wear}

Figures 3, 4, and 5 are the potentiodynamic polarization curves of the TLM alloy in different simulated physiological solutions with different wear conditions. The $i_{\text {corr }}$ determined from the Tafel region of the polarization curves and corrosion parameters of the TLM alloy with wear are shown in Table 5. It can be seen that the $E_{\text {corr }}$ of the test specimens are lower with loading $30 \mathrm{~N}$ than those with loading $20 \mathrm{~N}$. It suggests that the interaction between corrosion and wear at higher load is obvious. In other words, at higher load, the TLM alloy is corroded easily under the synergy of corrosion and wear. The friction frequency has little effect on the $E_{\text {corr }}$. The value of $E_{\text {corr }}$ is lowest in the PBS+HA while the $E_{\text {corr }}$ is highest in PBS. This situation shows that the TLM alloy has better wear resistance in PBS $+\mathrm{HA}$, because of the addition of HA. Under the action of $\mathrm{HA}$, the $i_{\text {corr }}$ was increased with increasing the friction frequency and load. Due to the
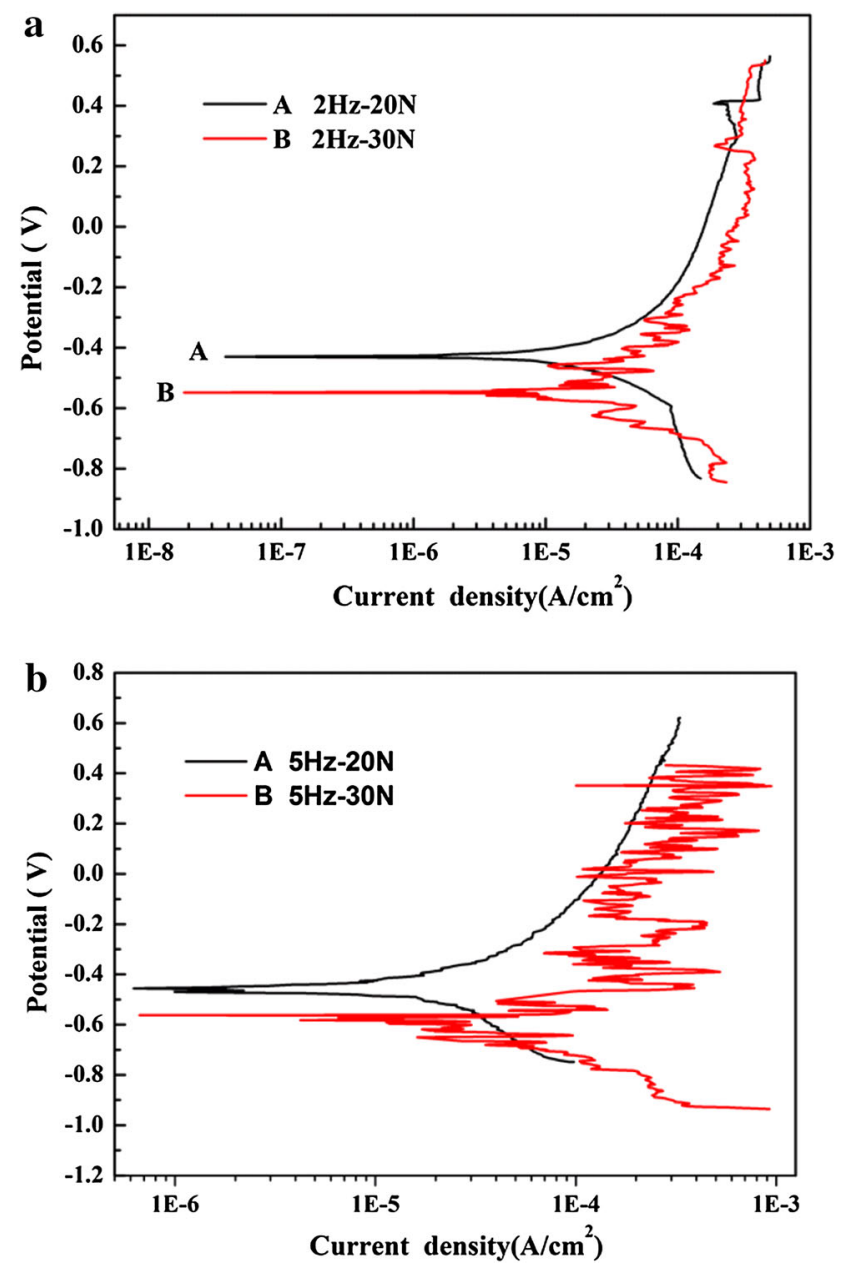

Fig. 3 Potentiodynamic polarization curves of the $\mathrm{Ti}-25 \mathrm{Nb}-3 \mathrm{Mo}-$ $3 \mathrm{Zr}-2 \mathrm{Sn}$ alloy under the synergy between wear and electrochemical corrosion in PBS with the loads of 20 and $30 \mathrm{~N}$ : a $2 \mathrm{~Hz} \mathrm{~b} 5 \mathrm{~Hz}$

viscoelasticity of HA, the wear debris could not disperse in the simulated solutions and concentrate the friction surface. These wear debris can be used as abrasive involved in the wear and aggravated the wear of the friction surface. Hence, the protective layer on the surface of the TLM alloy was damaged, and the corrosion resistant of the TLM alloy was decreased.

The $i_{\text {corr }}$ increases while the load increases, due to the role of the wear increases in the interaction at higher load. Besides, it also can be found that the volatility of anode polarization curves is improved with loading. The effect of wear was enhanced as load increased, the surface roughness of the test samples and the friction pair were increased, the friction were not stable, and resulting in the potentiodynamic polarization curves had major fluctuations. The simulated solutions can react with the TLM alloy and generate passive film on the friction surface [31]. At higher load, the passive film could be easily damaged, lose the protection for the alloy, and accelerate the corrosion. 

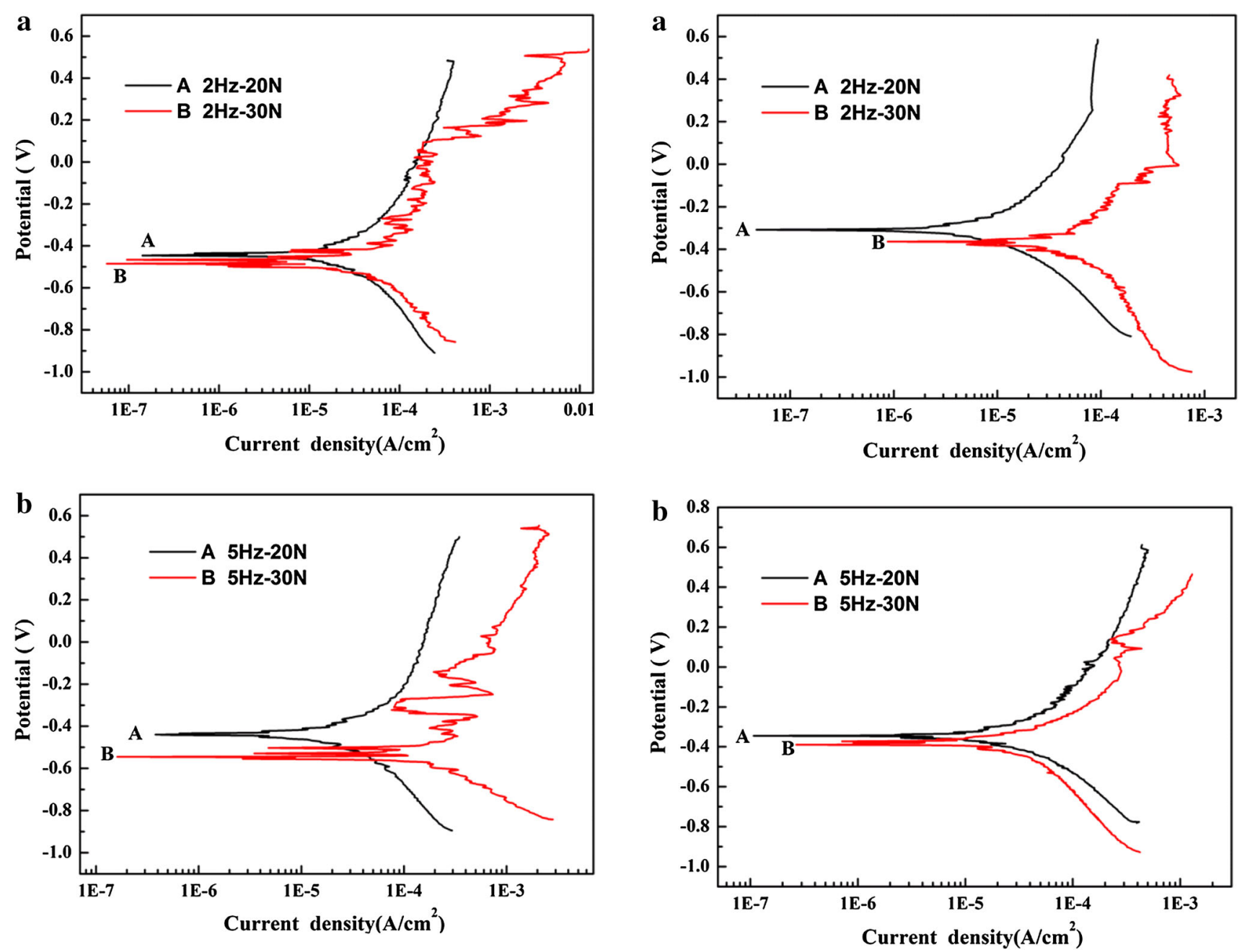

Fig. 4 Potentiodynamic polarization curves of the Ti-25Nb-3Mo$3 \mathrm{Zr}-2 \mathrm{Sn}$ alloy under the synergy between wear and electrochemical corrosion in PBS+BSA with the loads of 20 and $30 \mathrm{~N}$ : a $2 \mathrm{~Hz} \mathbf{b} 5 \mathrm{~Hz}$

In addition, compared with the static corrosion, the $E_{\text {corr }}$ and $i_{\text {corr }}$ increased. This illustrates that the wear plays an important role in decreasing the corrosion resistance of the TLM alloy. That is, wear accelerated the corrosion in these test conditions. The value of $i_{\text {corr }}$ is two orders of magnitude higher than those at static corrosion. This means that the wear rates increased noticeably. The results are consistent with the study of Mischler et al. [32]; the wearaccelerated corrosion due to depassivation of worn areas is likely to contribute significantly to the overall contact degradation.

\subsection{Wear Behaviors}

The simulated physiological solutions can reduce the wear between the friction pairs and decrease the friction coefficient. On the other hand, the surface roughness of the tested samples was changed with the development of the test. As

Fig. 5 The potentiodynamic polarization curves of the $\mathrm{Ti}-25 \mathrm{Nb}-$ $3 \mathrm{Mo}-3 \mathrm{Zr}-2 \mathrm{Sn}$ alloy under the synergy between wear and corrosion in PBS+HA with the loads of 20 and $30 \mathrm{~N}$ : a $2 \mathrm{~Hz}$ b $5 \mathrm{~Hz}$

a result of the mutual interactions of these factors, the friction coefficient should be present complex changes [33].

The friction coefficients of the TLM alloy under the interaction between corrosion and wear are presented in Fig. 6. It can be seen that the average friction coefficient is $0.3-0.5$. The value of friction coefficients is maximum in PBS while the value is minimum in PBS + BSA. This phenomenon shows that the PBS+BSA has better lubrication than PBS and PBS+HA. It is chiefly because the TLM alloy reacts with the PBS+BSA solution and forms passivation film, and these passivation films have better lubrication than those in PBS and PBS+HA. At high load of $30 \mathrm{~N}$, the friction coefficient is higher than that at $20 \mathrm{~N}$. When the applied load was larger, the surface roughness of the test samples would be increased, due to the severe worn surface. And the frictional resistance between the samples 
Table 5 Corrosion parameters of the Ti-25Nb-3Mo-3Zr-2Sn alloy under different wear-corrosion conditions

\begin{tabular}{lllcc}
\hline $\begin{array}{l}\text { Frequency } \\
(\mathrm{Hz})\end{array}$ & $\begin{array}{l}\text { Load } \\
(\mathrm{N})\end{array}$ & SPSs & $E_{\text {corr }}(\mathrm{V})$ & $\begin{array}{l}i_{\text {corr }} \\
\left(\times 10^{-7} \mathrm{~A} \mathrm{~cm}^{-2}\right)\end{array}$ \\
\hline 2 & 20 & PBS & -0.43 & 2.43 \\
& & PBS+BSA & -0.45 & 1.30 \\
& & PBS+HA & -0.31 & 2.06 \\
& \multirow{2}{*}{30} & PBS & -0.55 & 1.09 \\
& & PBS+BSA & -0.49 & 2.29 \\
& & PBS+HA & -0.36 & 2.88 \\
5 & PBS & -0.46 & 1.20 \\
& & PBS+BSA & -0.44 & 3.46 \\
& & PBS+HA & -0.35 & 3.50 \\
& \multirow{3}{*}{30} & PBS & -0.56 & 1.66 \\
& & PBS+BSA & -0.55 & 10.36 \\
& & PBS+HA & -0.39 & 8.06 \\
\hline
\end{tabular}

SPSs simulated physiological solutions

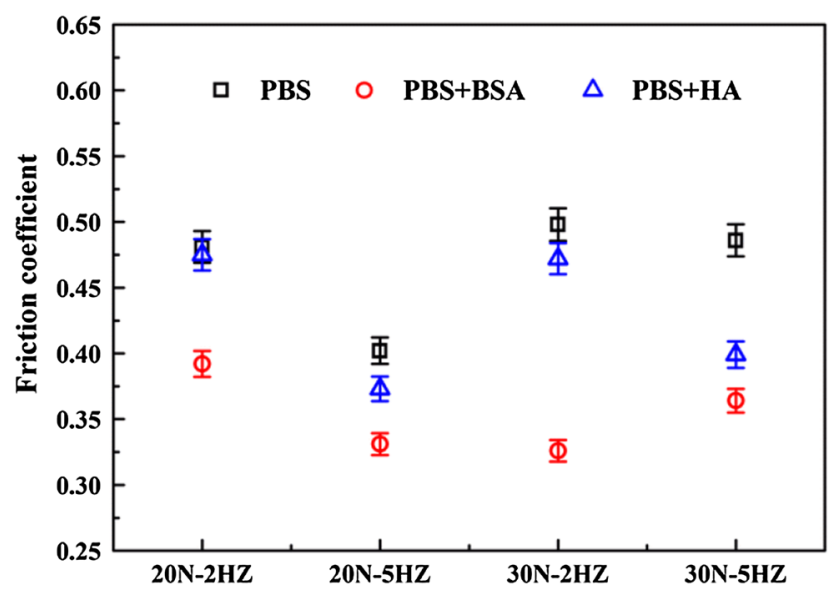

Fig. 6 Friction coefficient of the $\mathrm{Ti}-25 \mathrm{Nb}-3 \mathrm{Mo}-3 \mathrm{Zr}-2 \mathrm{Sn}$ alloy against a $\mathrm{Si}_{3} \mathrm{~N}_{4}$ ceramic counterface in various simulated physiological solutions

and ceramic ball would be increased in result; the coefficient increased with increasing loads. The higher friction coefficient observed at $30 \mathrm{~N}$ compared to $20 \mathrm{~N}$ corresponds well with the findings of Mischler et al. [34]; this situation can be explained by the higher stress imposed to the third body layer.

At low friction frequency of $2 \mathrm{~Hz}$, the friction coefficients are slightly higher than those at $5 \mathrm{~Hz}$, but the values of the friction coefficients are not changed significantly. This phenomenon shows that the influence of friction frequency on the friction coefficient is less than the load.

Under the coexisting condition of both corrosion and abrasion, the wear loss of the TLM alloy effected by both factors will be accelerated, and so did the wear rate. Figure 7 shows the wear rates of the TLM alloy in various

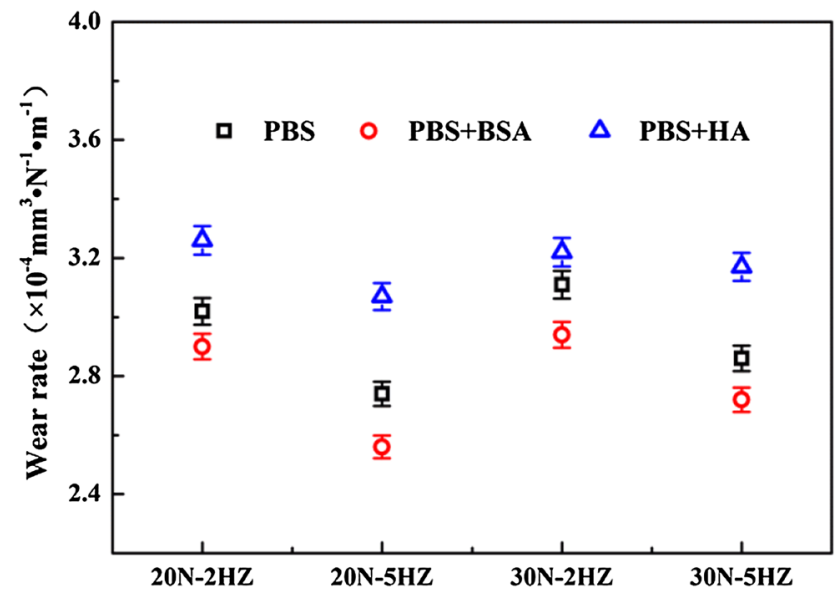

Fig. 7 Wear rates of the $\mathrm{Ti}-25 \mathrm{Nb}-3 \mathrm{Mo}-3 \mathrm{Zr}-2 \mathrm{Sn}$ alloy against a $\mathrm{Si}_{3} \mathrm{~N}_{4}$ ceramic counterface in various simulated physiological solutions

conditions. The values of the wear rates are in range between $2.5 \times 10^{-4}$ and $3.3 \times 10^{-4}$. In PBS+HA, the values of the wear rates are highest while the values are the lowest in PBS+BSA, due to the small friction in PBS+BSA. Corrosive components such as HA in PBS +HA can cause the corrosion and material removal of frictional pairs. The greatest amount of acidic compounds in PBS+HA leads to the serious corrosive wear and the highest wear rate, and this result is consistent with the research of $\mathrm{Xu}$ et al. [35].

Under the same loading condition, when the friction frequency is $2 \mathrm{~Hz}$, the values of the wear rates are higher than those at $5 \mathrm{~Hz}$. That is, the wear rates decreased with the increment of the friction frequency. This is because of a reduction of the contact time by increasing the frequency, which in turn reduces the speed of removing of the protective film, and therefore the wear was decreased [35]. But under the same friction frequency, the load has little effect on the wear rates.

The BSA was adsorbed on the frictional surfaces, and this would increase the lubrication effect between the friction pairs. By contrast, the HA on the frictional surfaces not only has the effect of reducing-friction and anti-wear but also decreased accelerate wear. These phenomenons are attributed to the interaction between the corrosion and wear. At the same time, acidic compounds caused the corrosion and increased wear.

\subsection{Corrosive Wear Morphologies}

The typical SEM morphologies of worn surfaces of the TLM alloy are shown in Fig. 8, which the alloy against the $\mathrm{Si}_{3} \mathrm{~N}_{4}$ counterface by using a normal load of $20 \mathrm{~N}$ with a friction frequency of $5 \mathrm{~Hz}$ on a reciprocating friction and wear tester. 

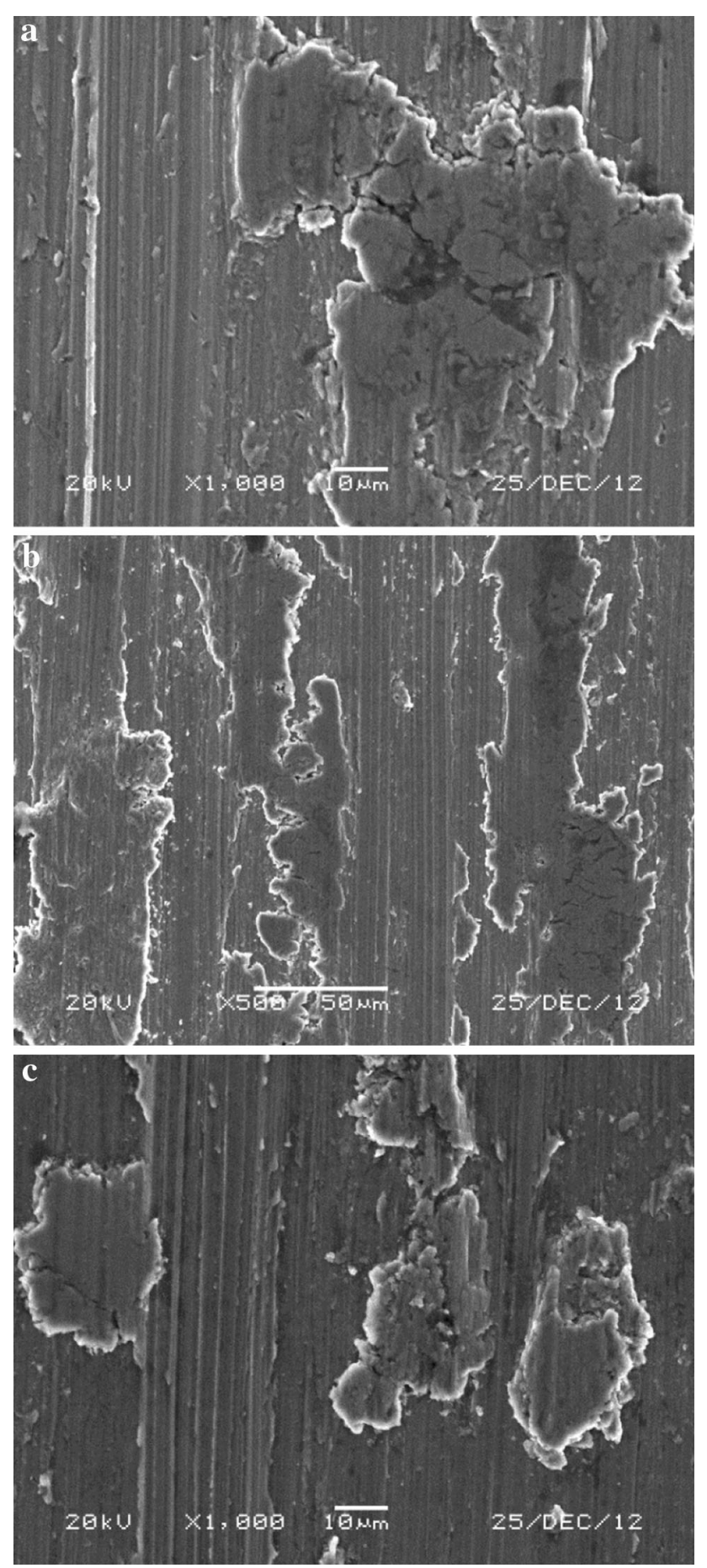

Fig. 8 SEM observation of worn surfaces for the Ti-25Nb-3Mo$3 \mathrm{Zr}-2 \mathrm{Sn}$ alloy against a $\mathrm{Si}_{3} \mathrm{~N}_{4}$ ceramic counterface using a normal load of $20 \mathrm{~N}$ with a friction frequency of $5 \mathrm{~Hz}$ on a reciprocating friction and wear tester in different simulated physiological solutions: a PBS; b PBS+BSA; c PBS+HA

Due to the higher load-bearing capability of the TLM matrix, the metallic appearance is not observed on the worn surfaces. The plastic grooves and deformation in

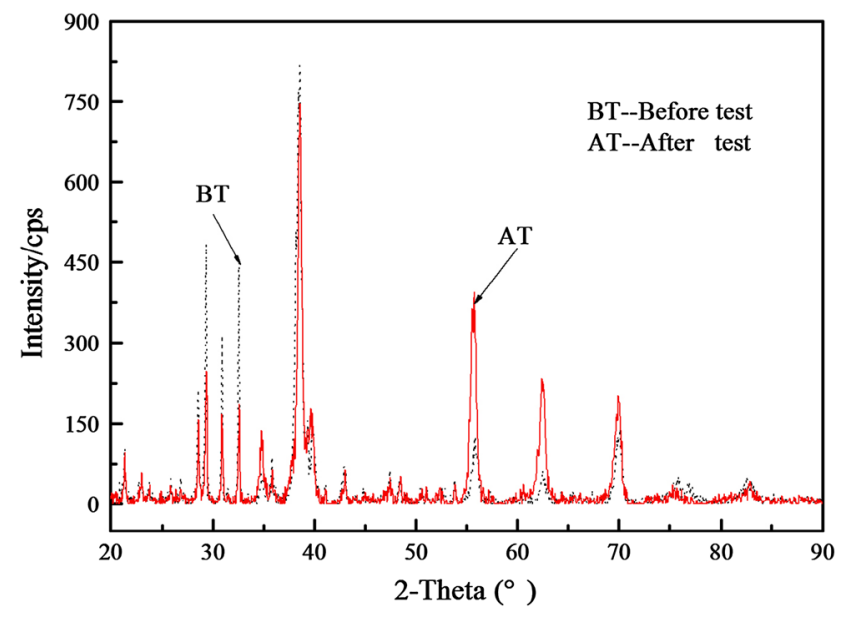

Fig. 9 The XRD patterns of the Ti-25Nb-3Mo-3Zr-2Sn alloy before and after wear in PBS+HA

different sizes, and the metallic particles adhesion are obviously observed in these worn surfaces. The relative motion of the two surfaces induced plastic deformation [33]. In result, severe material transfer through abrasive and adhesive wear is likely to occur when the TLM alloy against the $\mathrm{Si}_{3} \mathrm{~N}_{4}$ counterface, leading to the fluctuation of friction coefficients (Fig. 7). The visible grooves inside the worn surfaces are parallel to the sliding movement, showing a predominant abrasive mechanism, and the similar results are acquired by Runa et al. [28] and Abad et al. [36]. The abrasive mechanism was induced by the wear debris.

The sizes of plastic grooves in Fig. 8 correspond to the wear rates in Fig. 7. In Fig. 8a, the grooves are narrow and shallow, leading to the wear rates are lowest in PBS+BSA. In contrast, in PBS+HA (Fig. 8c), the wear rates are highest due to the deep and wide grooves which were produced during the process of corrosion and wear.

The shallow and continuous passive films and some metal particles are observed on the worn surfaces in Fig. 8. The metal particles were pulled down from the worn surface. The metal particles and passive films are adhered on the worn surface. The adhesive passive films showed excellent protection to the severe metallic wear, but the electrochemical corrosion occurred in the passive films. This may be due to the protection layer on the metallic surfaces that were damaged by wear, and the fresh surfaces were exposed to the corrosive liquid. The apparent decrease of wear rate and the continuous formation of passive films during the wear testing proved a dominant oxidative mechanism of the TLM alloy surfaces against the $\mathrm{Si}_{3} \mathrm{~N}_{4}$ counterface [37]. In accordance with the above analysis the results of the corrosion and wear, the tribological mechanism can be attributed to 

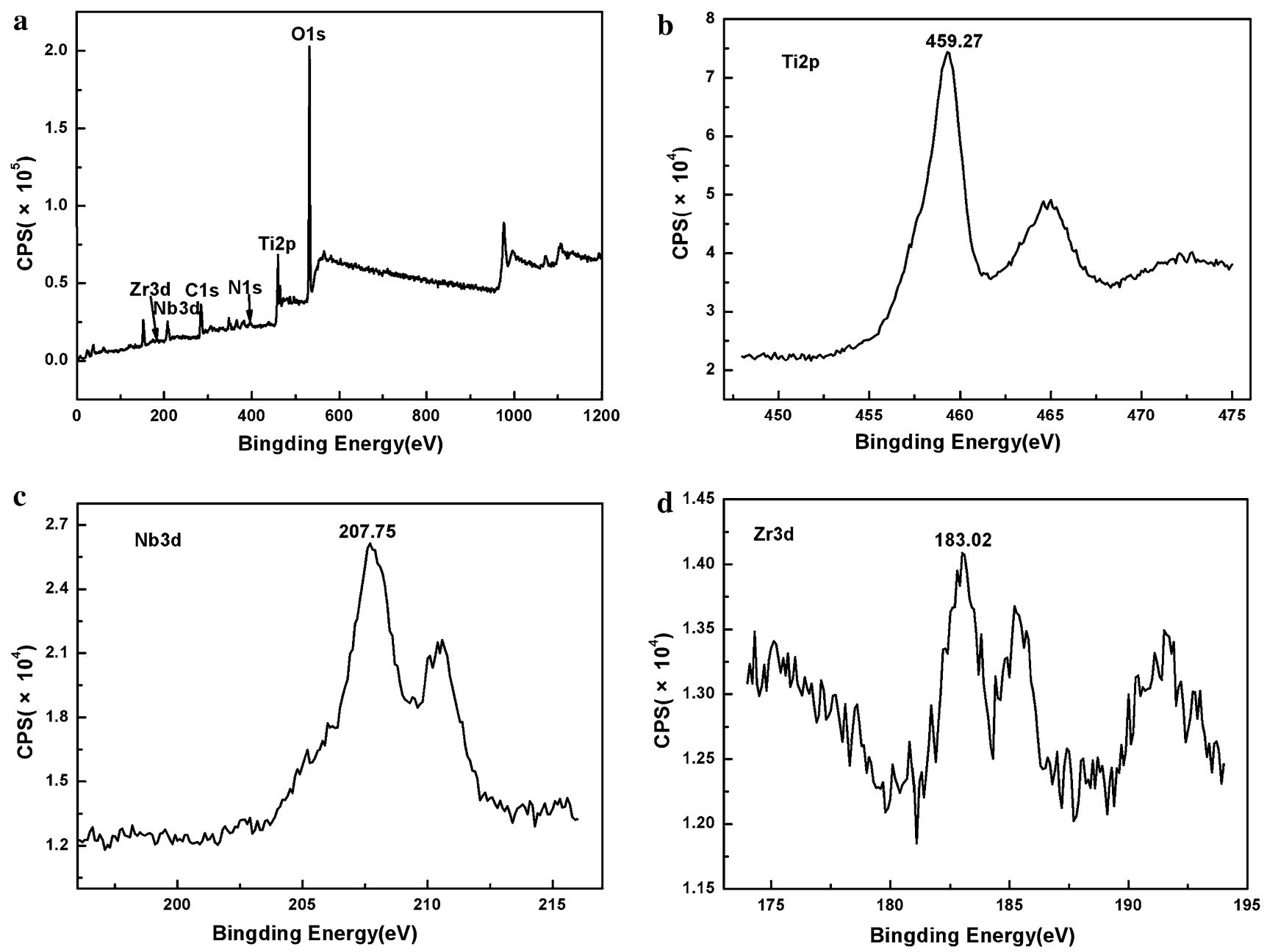

Fig. 10 The XPS spectra the Ti-25Nb-3Mo-3Zr-2Sn alloy in PBS+HA: a The XPS spectra the Ti-25Nb-3Mo-3Zr-2Sn alloy after wear in PBS+HA; b The Ti2p XPS spectra; $\mathbf{c}$ The Nb3d XPS

spectra; d The Zr3d XPS spectra; e The O1s XPS spectra; f The C1s XPS spectra; g The N1s XPS spectra

typical corrosive wear, and the main wear mechanisms are abrasive with adhesive wear.

In order to find out the composition of the passive film, XRD and XPS were selected to use. After tested in PBS + HA, the sample was chosen to do the tests, because of the sample has the highest wear rate. Figure 9 shows the XRD results of the sample. As can be seen from the fig, before and after test, the positions of the diffraction peaks are unchanged basically. It implied that the chemical composition of the sample surface was not change, and the protein composition had not been found. It is probably because the less content of protein and was not displayed. Applications XPS can be used to analyze the chemical composition of the sample surface. Figure 10 shows the XPS results of the tested sample. According to the narrow

spectrum scan results of Ti2p, $\mathrm{Zr} 3 \mathrm{~d}, \mathrm{Nb} 3 \mathrm{~d}, \mathrm{O} 1 \mathrm{~s}, \mathrm{C} 1 \mathrm{~s}$, and N1s, the spectrum peaks of each element were obtained, and the results were 459.27, 183.02, 207.75, 531.12, 383.14 , and $395.95 \mathrm{eV}$, respectively. Compared with the Binding energy data, then based on the position of Ti2p, $\mathrm{Zr} 3 \mathrm{~d}$ and $\mathrm{Nb} 3 \mathrm{~d}$ and the shape of O1s peak, the composition of the passive films was determined, they are $\mathrm{TiO}_{2}, \mathrm{ZrO}_{2}$, and $\mathrm{Nb}_{2} \mathrm{O}_{5}$. Due to the atomic percentage of Mo and $\mathrm{Sn}$ is lower, while the two elements were found during the process of scanning, but the values of binding energy were not acquired. But according to the percentage of oxygen atoms, it can be determined that the passive films also include $\mathrm{Mo}_{2} \mathrm{O}_{5}$ and $\mathrm{Sn}_{2} \mathrm{O}_{3}$. Besides, the $\mathrm{C}$ and $\mathrm{N}$ elements are also found in Fig. 10, and it implied that the protein was adsorbed on the tested sample surface. 

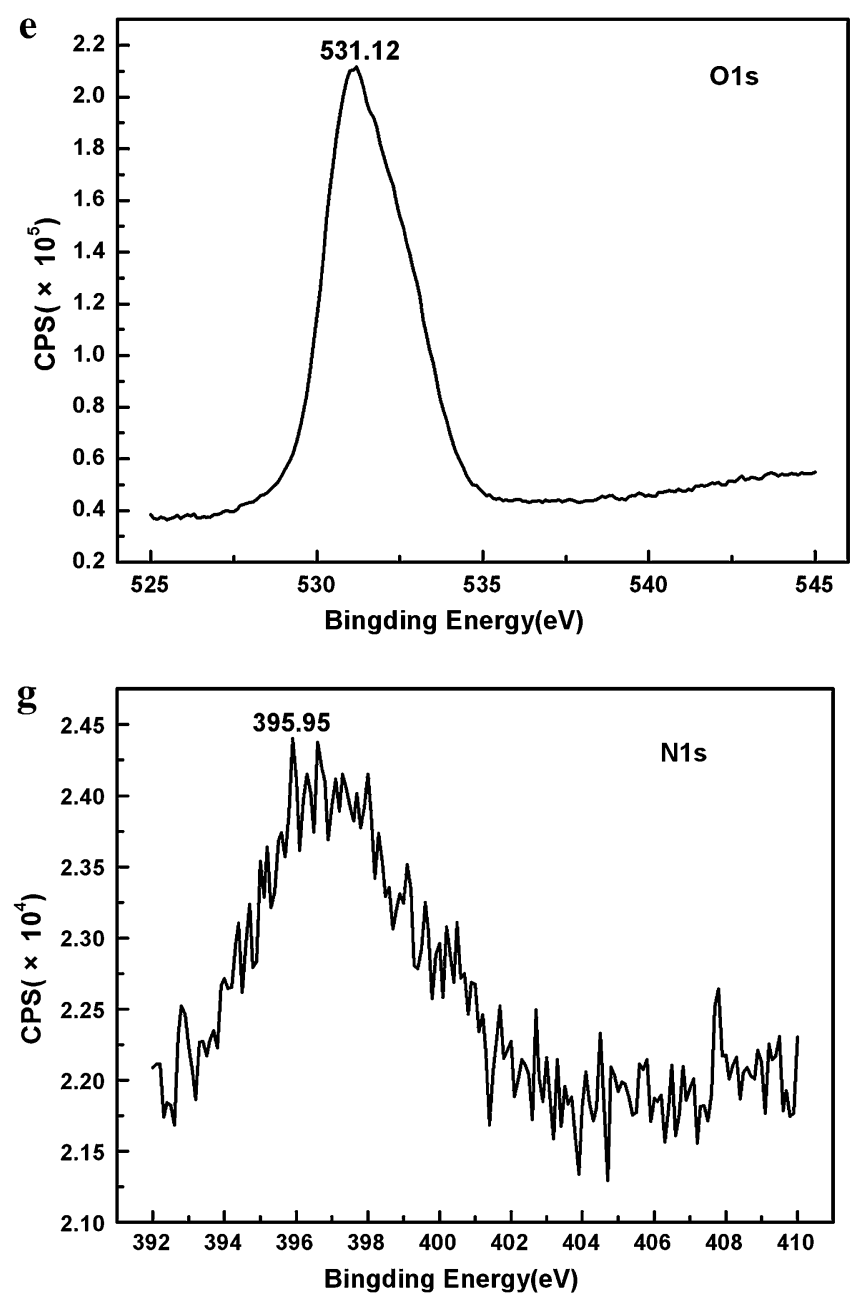

Fig. 10 continued

\section{Conclusions}

The wear and electrochemical corrosion behavior of the TLM alloy was studied in different simulated physiological solutions. The following conclusions could be drawn from the results:

(1) The chemical composition of the simulated physiological solutions has effect on the tribo-electrochemical behavior of the TLM alloy. Under the static corrosion, the corrosion tendency of the TLM alloy is the most obvious in PBS+HA, while the corrosion rate is fastest in PBS+BSA.

(2) Compared with static corrosion, the corrosion tendency of the TLM alloy is enhanced by wear. The values of $i_{\text {corr }}$ are two orders of magnitude higher than those under the static corrosion, suggesting that the wear-accelerated corrosion.

(3) Under wear and electrochemical corrosion, the wear rate of the TLM alloy mutually affected by both

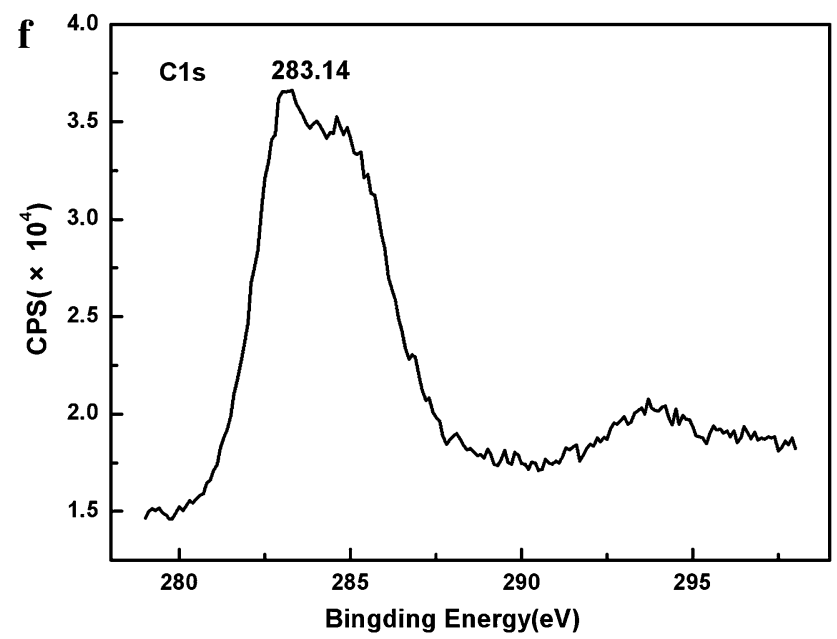

factors will be accelerated. Plastic grooves and deformation are observed on the worn surfaces of the TLM alloy. The tribological mechanisms are typical corrosive wear, and the main wear mechanisms are abrasive with adhesive wear. The composition of the passive films includes $\mathrm{TiO}_{2}, \mathrm{ZrO}_{2}$, $\mathrm{Mo}_{2} \mathrm{O}_{5}, \mathrm{Sn}_{2} \mathrm{O}_{3}$, and $\mathrm{Nb}_{2} \mathrm{O}_{5}$.

Acknowledgments The authors would like to acknowledge the financial support of the Starting Foundation for Talents Returning from Overseas of Ministry of Education of China (2012-940) and the National Natural Science Foundation of China (50405005, 31000430, and 51401027).

\section{References}

1. Leyens C, Peters M (2003) Titanium and Titanium Alloys: Fundamentals and Applications. Wiley, Weinheim

2. Majumdar P, Singh SB, Chakraborty M (2011) The role of heat treatment on microstructure and mechanical properties of $\mathrm{Ti}-$ 
3Zr-13Nb alloy for biomedical load bearing applications. J Mech Behav Biomed Mater 4:1132-1144

3. Geetha M, Singh AK, Asokamani R, Gogia AK (2009) Ti based biomaterials, the ultimate choice for orthopaedic implants: a review. Prog Mater Sci 54:397-425

4. Rack HJ, Qazi JI (2006) Titanium alloys for biomedical applications. Mater Sci Eng C 266:1269-1277

5. Ikeda M, Komatsu SY, Sowa I et al (2002) Aging behavior of the $\mathrm{Ti}-29 \mathrm{Nb}-13 \mathrm{Ta}-4.6 \mathrm{Zr}$ new beta alloy for medical implants. Metall Mater Trans A 33:487-493

6. Eisenbarth E, Velten D, Muller M et al (2004) Biocompatibility of beta stabilizing elements of titanium alloys. Biomaterials 25:5705-5713

7. Fojt J (2012) Ti-6Al-4V alloy surface modification for medical applications. Appl Surf Sci 262:163-167

8. Zhao CL, Zhang XN, Cao P (2011) Mechanical and electrochemical characterization of Ti-12Mo-5Zr alloy for biomedical application. J Alloy Compd 509:8235-8238

9. Ho WF, Wu SC, Hsu SK et al (2012) Effects of molybdenum content on the structure and mechanical properties of as-cast $\mathrm{Ti}-$ 10Zr-based alloys for biomedical applications. Mater Sci Eng C 32:517-522

10. Gabriel SB, Panaino JVP, Santos ID et al (2012) Characterization of a new beta titanium alloy, Ti-12Mo-3Nb, for biomedical applications. J Alloy Compd 536S:S208-S210

11. Niinomi M (2003) Recent research and development in titanium alloys for biomedical applications and healthcare goods. Sci Technol Adv Mater 4:445-454

12. Yu S, Yu ZT, Wang G et al (2011) Biocompatibility and osteoconduction of active porous calcium-phosphate films on a novel Ti-3Zr-2Sn-3Mo-25Nb biomedical alloy. Colloids Surf B $85: 103-115$

13. Huang R, Han Y (2013) The effect of SMAT-induced grain refinement and dislocations on the corrosion behavior of $\mathrm{Ti}-$ 25Nb-3Mo-3Zr-2Sn alloy. Mater Sci Eng, C 33:2353-2359

14. Kent D, Xiao WL, Wang G et al (2012) Thermal stability of an ultrafine grain $\beta$-Ti alloy. Mater Sci Eng A 556:582-587

15. Bermingham MJ, McDonald SD, Buddery AJ et al (2011) Processing considerations for cast $\mathrm{Ti}-25 \mathrm{Nb}-3 \mathrm{Mo}-3 \mathrm{Zr}-2 \mathrm{Sn}$ biomedical alloys. Mater Sci Eng C 31:1520-1525

16. Kent D, Wang G, Yu ZT et al (2011) Strength enhancement of a biomedical titanium alloy through a modified accumulative roll bonding technique. J Mech Behav Biomed Mater 4: 405-416

17. Xu P, Lin CX, Zhou CY et al (2014) Wear and corrosion resistance of laser cladding AISI 304 stainless steel/ $/ \mathrm{Al}_{2} \mathrm{O}_{3}$ composite coatings. Surf Coat Technol 238:9-14

18. Lgried M, Neville Liskiewicz T (2012) Electrochemical investigation of corrosion and wear interactions under fretting conditions. Wear 282-283:52-58

19. Esfandiari M, Dong H (2007) The corrosion and corrosion-wear behaviour of plasma nitride $17-4 \mathrm{PH}$ precipitation hardening stainless steel. Surf Coat Technol 202:466-478
20. Mohan L, Anandan C (2013) Wear and corrosion behavior of oxygen implanted biomedical titanium alloy $\mathrm{Ti}-13 \mathrm{Nb}-13 \mathrm{Zr}$. Appl Surf Sci 282:281-290

21. Yildiz F, Yetim AF, Alsaran A (2009) Wear and corrosion behaviour of various surface treated medical grade titanium alloy in bio-simulated environment. Wear 267:695-761

22. Khan MA, Williams Williams DF (1996) In-vitro corrosion and wear of titanium alloys in the biological environment. Biomaterials 17:2117-2126

23. Suresh KS, Geetha M, Richard C et al (2012) Effect of equal channel angular extrusion on wear and corrosion behavior of the orthopedic $\mathrm{Ti}-13 \mathrm{Nb}-13 \mathrm{Zr}$ alloy in simulated body fluid. Mater Sci Eng C 32:763-771

24. Cvijovic-Alagic I, Cvijovic Z, Mitrovic S et al (2011) Wear and corrosion behaviour of $\mathrm{Ti}-3 \mathrm{Nb}-13 \mathrm{Zr}$ and $\mathrm{Ti}-6 \mathrm{Al}-4 \mathrm{~V}$ alloys in simulated physiological solution. Corros Sci 53:796-808

25. Souza JM, Barbosa SL, Ariza E et al (2012) Simultaneous degradation by corrosion and wear of titanium in artificial saliva containing fluorides. Wear 292-293:82-88

26. Lei MK, Dong ZH, Zhang $Z$ et al (2007) Wear and corrosion resistance of Ti6Al4V alloy irradiated by high-intensity pulsed ion beam. Surf Coat Technol 201:5613-5616

27. Bai Y, Li SJ, Prima F et al (2012) Electrochemical corrosion behavior of $\mathrm{Ti}-24 \mathrm{Nb}-4 \mathrm{Zr}-8 \mathrm{Sn}$ alloy in a simulated physiological environment. Appl Surf Sci 258:4035-4040

28. Runa MJ, Mathew MT, Rocha LA (2013) Tribocorrosion response of the Ti6Al4V alloys commonly used in femoral stems. Tribol Int 68:85-93

29. Valero Vidal C, Olmo Juan A, Igual Munoz A (2010) Adsorption of bovine serum albumin on CoCrMo surface: effect of temperature and protein concentration. Colloid Surf B 80:1-11

30. Cheng XL, Roscoe SG (2005) Corrosion behavior of titanium in the presence of calcium phosphate and serum proteins. Biomaterials 26:7350-7356

31. Ding HY, Dai ZD, Zhou F et al (2007) Sliding friction and wear behavior of TC11 in aqueous condition. Wear 263:117-124

32. Mischler S, Munoz A (2013) Wear of CoCrMo alloys used in metal-on-metal hip joints: a tribocorrosion appraisal. Wear 297:1081-1094

33. Virtanen S, Milošev I, Gomez-Barrena E et al (2008) Special modes of corrosion under physiological and simulated physiological conditions. Acta Biomater 4(3):468-476

34. Hiromoto S, Mischler S (2006) The influence of proteins on the fretting-corrosion behaviour of a Ti6Al4V alloy. Wear 261:1002-1011

35. Xu YF, Hu XG, Yuan K (2014) Friction and wear behaviors of catalytic methylesterified bio-oil. Tribol Int 71:168-174

36. Abad MD, Sanchez-Lopez JC (2013) Tribological properties of surface-modified Pd nanoparticles for electrical contacts. Wear 297:943-951

37. Lei MK, Ou YX, Wang KS et al (2011) Wear and corrosion properties of plasma-based low-energy nitrogen ion implanted titanium. Surf Coat Technol 205:4602-4607 